\title{
Socials science
}

\author{
The last three months have been a dispiriting experience for most plant scientists. But this period of collective \\ isolation is demonstrating the usefulness of alternative ways to come together as a community.
}

T's: here was a time, not that long ago, when scientific publishing revolved around paper. Having done their research, authors sent, by mail, multiple copies of their manuscripts typed out on paper to editors who then posted them to reviewers. The authors would hope that their study would eventually be published in an issue of a journal, printed on paper. Such an issue would bind together a large number of studies to reduce the cost of postage to readers and universities, and so that it could be stacked neatly and tidily on library shelves.

In some ways, these processes have hardly changed except that the reams and reams of paper that used to be the medium for exchanges of information have gone. In others, everything has changed. Now there are a multitude of routes for scientific communication: formal, informal and everything in between. For research to flourish, we must all embrace at least some of these new outlets, and COVID-19 is only accelerating their adoption.

With so many journals publishing so many research papers every week, a question that every researcher should ask themselves is "how can I get my peers to notice my work?". One of the best answers to that is Twitter. From talking to scientists at conferences or when visiting universities, it is clear that aside from having searches set up on indexing sites like PubMed or Google Scholar, a lot of researchers hear about exciting new work through recommendations on Twitter.

Most journals by now have a Twitter account, although these are often quite dull, featuring nothing but a stream of alerts to just-published papers. We hope that the reason our Twitter account now has over 20,000 followers is that we are more varied than that. Elsewhere, our friend Mary Williams (@PlantTeaching) of The Plant Cell is a great source of information, as are Plant Editors (@PlantEditors) and Plants and Pipettes (@plantspipettes), though more on them later. Tweets tagged with \#PlantSci, \#PlantScience or similar are also generally good, but best of all is following people and labs you know (or whose work you know) to create a 'hive mind' to find studies of particular and personal interest, and all in only a few hundred characters.

At a different scale, there are the preprint servers which serve to give preliminary looks at studies before peer review or formal publication. The best known of these is bioR $\chi$ iv (https://www.biorxiv.org/), which usually posts several plant biology papers a day. Some papers that appear on preprint servers never appear in 'official' journals, as this medium provides all the exposure that they need. However, for many researchers and journals, pre-printing is becoming integrated into the submission and review process.

Most journals do not let the posting of papers on a preprint server affect their consideration of submission of the same work, while some (including Current Biology, eLife and Plant Cell) have systems in place for direct submission of studies from bioR $\chi i v$. Another quickly growing preprint server, Research Square (https://www. researchsquare.com/), can operate in the other direction. When submitting to a host of journals (including BMC Plant Biology and Rice), authors are given the opportunity to directly post their submission on the 'In Review' section of Research Square. The preprint remains permanently on Research Square no matter what the fate of the submission.

Within the next few weeks, the Nature Research journals, including Nature Plants, will be offering this facility, although the preprints will be labelled as 'Under Review at Nature Research' rather than identifying an individual journal, as is the case with some other publications. Of course, preprint servers do not serve the needs of all researchers and all items of research, and whether you choose to post or not will not affect in any way the consideration of your studies at Nature Plants.

One medium that has been given a boost to the point of renaissance by the internet is sound broadcasting. Radio programming needed bulky engineering to reach people in even relatively small geographical areas, but podcasts can be created by almost anyone and distributed globally at a very low cost, and so are able to cater for specialist audiences, even plant scientists. Journals and publishers have diversified into podcasts. Taproot (https:// bit.ly/2Br3 $\mathrm{Te} 9$ ) from the American Society of Plant Biologists is an award-winning example. However, if you want your plant science to be more individualized, it is worth listening to In Defence of Plants
(https://bit.ly/31A2QTQ) or Plants and Pipettes (https://bit.ly/3ePdlXd), both of which are hosted by early career scientists.

Something that all of us are having to cope with is the lack of physical conferences, seminars and lectures. Here, the internet and social media have spectacularly come to our rescue. Many conferences that would have been taking place this year are rescheduling. For example, I should be writing this Editorial between sessions at Plant Biology Europe in Turin before catching a plane to Cold Spring Harbor Laboratory, to talk at the Frontiers and Techniques In Plant Science course, and then continuing west to Seattle a few days later for the International Conference on Arabidopsis Research. All of these and many other meetings, small and large, have been postponed for 12 months.

Other gatherings are turning virtual, most notably Plant Biology 2020 (https://bit. ly/3eOztkD), which, rather than descending on Washington, D.C. for five days, will be spending the last week of July as a 'World Summit', in which essentially everything that would have been going on will be recreated online. The organizers of the Seventh International Horticulture Research Conference (https://bit.ly/2Br3Te9) have taken a different tack. Freed from the time constraints that arise from having to bring delegates and speakers together, they have spread their program over the entirety of July, with sessions timetabled to be accessible wherever in the world potential attendees are locked down.

Seminar series and lectures have been moving online too, or being 'born-digital' specifically to keep research communities together. These are proving extremely popular, attracting far larger attendances than organizers would have dared to hope for under normal circumstances.

These developments in communication have been available for many years, but the enforced seclusions needed to address COVID-19 are dramatically demonstrating both their potentials and advantages. By the time anti-virus measures have been scaled back to hardly noticeable levels, our adventures in distanced community will likely have become the norm.

Published online: 14 July 2020 https://doi.org/10.1038/s41477-020-0736-X 